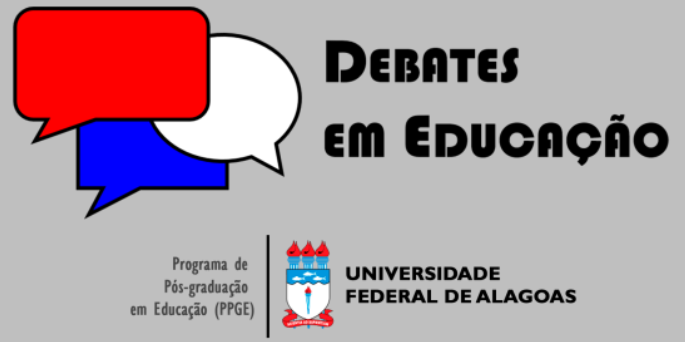

ISSN Eletrônico 2175-6600

Vol. 12 | Número Especial 2 | 2020

Elisangela Leal de Oliveira Mercado

(9) iD

Universidade Federal de Alagoas (UFAL)

elisangelamercado@gmail.com

Karla Maria Martins Santos Pereira

(9) iD

Universidade Federal de Alagoas (UFAL)

karlapereiraufal@hotmail.com

Liziane Medeiros Nascimento do Amor

Divino

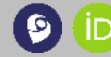

Universidade Federal de Alagoas (UFAL) lizi_medeiros@hotmail.com

\section{ANÁLISE DOS PROJETOS PEDAGÓGICOS DOS CURSOS LICENCIATURA: ESTAMOS PREPARANDO PROFESSORES PARA LECIONAR ESTUDANTES COM DEFICIÊNCIA?}

\section{RESUMO}

Este artigo investigou como ocorre a preparação dos futuros professores para a inclusão escolar. A metodologia consistiu numa pesquisa qualitativa de cunho exploratório, por meio de pesquisa documental com base na pesquisa bibliográfica (CHACON, 200I; VITALIANO, 2008; VITALIANO; DALL'ACQUA, 20I2) e documentos legais referentes ao tema. Foram analisadas as ementas e matriz curricular de dezesseis Projetos Pedagógicos de Cursos (PPC) de licenciatura da Universidade Federal de Alagoas (UFAL), buscando identificar os saberes pedagógicos adequados aos futuros professores, que permitam a atuação destes na Inclusão Escolar. Os achados revelaram que as problemáticas, decorrentes da lacuna na formação inicial de professores da Educação Básica em situação de Inclusão Escolar estão longe de serem superadas.

Palavras-chave: Formação de Professores. Projeto Pedagógico de Curso. Pessoa com Deficiência.

\section{ANALYSIS OF THE PEDAGOGICAL PROJECTS OF THE LICENSE COURSES: ARE WE PREPARING TEACHERS TO TEACH STUDENTS WITH DISABILITIES?}

\section{ABSTRACT}

This article investigated how future teachers prepare for school inclusion. The methodology consisted of a qualitative research of an exploratory nature, through documentary research based on bibliographic research (CHACON, 200I; VITALIANO, 2008; VITALIANO; DALL'ACQUA, 20I2) and legal documents related to the theme. The menus and curricular matrix of sixteen Pedagogical Course Projects (PPC) for undergraduate courses at the Federal University of Alagoas (UFAL) were analyzed, seeking to identify the appropriate pedagogical knowledge for future teachers, which would allow their performance in School Inclusion. The findings revealed that the problems resulting from the gap in the initial education of Basic Education teachers in a situation of School Inclusion are far from being overcome.

Keywords: Teacher Education. Pedagogical Course Project. Disabled Person.

Submetido em: 17/09/2020

Aceito em: 13/09/2020

Publicado em: 30/I2/2020

dc http://dx.doi.org//0.28998/2175-6600.2020v 12nEsp2p292-3।4 


\section{INTRODUÇÃO}

A discussão da inclusão da pessoa com deficiência no ambiente escolar é ampliada, a partir do momento em que a educação escolar passa a ser direito de todos e dever do Estado e da família, conforme preconiza o Artigo 205 da Constituição Federal do Brasil (BRASIL, 1988). Com isso, os cursos de formação de professores preveem na sua matriz curricular, conhecimentos que subsidiem aos futuros professores, adequações e estratégias necessárias para atender e proporcionar o desenvolvimento e a aprendizagem dos estudantes com deficiência em salas de aula comum.

A formação inicial docente, vinculada a discussão do processo de aprendizagem da pessoa com deficiência em tempo de Inclusão Escolar, é vista como ferramenta essencial para que este profissional consiga atuar em um contexto educacional inclusivo. A política educacional brasileira prevê que todos os cursos de formação de professores, em nível médio ou superior, preparem o professor para incluir e garantir o direito de aprender aos estudantes com deficiências.

Este artigo originou-se do interesse em analisar nos PPC de licenciatura da UFAL, a formação docente para inclusão na escola regular de estudantes com deficiências, Transtornos Globais do Desenvolvimento (TGD) e altas habilidades ou superdotação. A necessidade da realização deste estudo se deu tanto pelo crescente número desses estudantes matriculados nos sistemas educacionais alagoano (ALAGOAS, 2017; 2018) impulsionado pela Lei de Diretrizes e Bases da Educação Nacional (LDBEN) Lei n 9.394/I 996 (BRASIL, 1996), pela Política Nacional de Educação Especial na Perspectiva da Educação Inclusiva (PNEE-EI) (BRASIL, 2008) e pelo Decreto n 6.949/2009 (BRASIL, 2009); quanto pelo relato incessante de professores da educação básica de que não foram preparados na licenciatura para lecionar estes estudantes na sala de aula comum.

Acompanhando o processo histórico dessa discussão, no início dos anos 1990, diante do cenário de integração/inclusão escolar, o Ministério da Educação (MEC) publicou a Portaria nº I.793/I 994 (MEC, 1994) com a finalidade dos curso de formação de professores e de Psicologia incluírem na grade curricular a disciplina "Aspectos Ético-Político-Educacionais da Normalização e Integração da Pessoa Portadora de Necessidades Especiais '", além dos cursos das áreas de Saúde e Serviço Social incluírem no PPC conteúdos relacionados a essa temática.

Chacon (200I) analisou as grades curriculares dos cursos de Pedagogia e de Psicologia de 33 universidades e constatou que poucos cursos criaram a disciplina recomendada pelo MEC ou abordavam este tipo de conteúdo nas disciplinas ofertadas ao longo do curso. Rodrigues (2005) também alerta que muitos cursos de formação inicial de professores não discutem a área de necessidades educativas especiais

\footnotetext{
' Nomenclatura utilizada na época, hoje substituída pelo termo Pessoa com Deficiência, conforme determina o Decreto $\mathrm{n}^{\circ}$ 6.949/2009 (BRASIL, 2009).
} 
ou, por vezes omitem conhecimentos pedagógicos relacionados a como as pessoas com deficiências aprendem. Resultado semelhante foi observado nas pesquisas de Vitaliano (2008), Vitaliano e Dall'Acqua (2012), que identificaram nos licenciados comportamentos de temor e sensação de incapacidade quando apresentados aos estudantes com deficiências.

Desde a publicação da Portaria n $1.793 / 1994$, num cenário de aumento significativo de estudantes com deficiências em salas de aula comum e de reformulação dos PPC em atendimento a Resolução CNE/CP n 2/20I5 (MEC, 20I5), este estudo busca responder se os PPC de Licenciatura da UFAL atendem as determinações legais e anseios reais de preparar futuros professores para lecionar em ambiente educacional inclusivo.

No cenário das políticas educacionais inclusivas, que a cada ano vemos o aumento do número de estudantes com deficiências em sala de aula comum (ALAGOAS, 2017; 2018), faz-se necessário repensar a formação de professores a começar pelos PPC ofertados. Com a homologação da Resolução CNE/CP n 2/20 I 5 (MEC, 20I5) estabeleceu-se que os cursos de formação inicial e continuada de Profissionais do Magistério para a Educação Básica em nível superior, incluam conhecimentos específicos e pedagógicos relacionadas à Educação Especial, em seus PPC, como medida de preparação dos futuros professores para atuarem num sistema educacional inclusivo, estimulado pelo Decreto nº 6.949/2009 (BRASIL, 2009).

Tomando como base essa situação, analisaremos como ocorre a preparação dos futuros professores para inclusão escolar, a partir dos PPC de licenciatura ofertado pela UFAL, em atendimento ao Artigo 59, Inciso III, da LDBEN:

Os sistemas de ensino assegurarão aos educandos com deficiência, transtornos globais do desenvolvimento e altas habilidades ou superdotação: III - professores com especialização adequada em nível médio ou superior, para atendimento especializado, bem como professores do ensino regular capacitados para a integração desses educandos nas classes comuns (BRASIL, 1996, p.44, grifo nosso)

Considerando que os professores da educação básica devem ser formados para atuar em salas de aula em que há estudantes com e sem deficiência matriculados, a formação docente é um aspecto complexo e necessário diante do esforço de implementação de um sistema educacional inclusivo. A despeito dessa questão, Mendes (2008) defende que a política de formação de professores é um dos pilares para a construção da inclusão escolar. Dessa forma, é de suma importância a análise dos PPC de licenciatura, no tocante às recomendações referentes a formação docente com vistas a garantia do direito de aprender dos estudantes com deficiência. Na análise documental dos PPC, identificaremos na grade curricular e ementas dos componentes curriculares se estes proporcionam saberes pedagógicos adequados para os licenciandos atuarem na complexidade do processo de Inclusão Escolar, seja no componente curricular de Educação Especial propriamente dito ou outros relacionados à temática em estudo. 


\section{A PERSPECTIVA hISTÓRICA, POLÍtica e edUCACIONAL DA INCLUSÃO ESCOLAR}

É fundamental tratar de Educação Inclusiva num país com muitos problemas relacionados às questões sociais e com grande parcela da população sem escolarização. $\bigcirc$ processo histórico do acesso das pessoas com deficiência à escola regular é permeado pela exclusão e segregação. Crianças com deficiências, até meados do século $X X$, foram marginalizadas e segregadas em instituições especializadas que, por vezes, retiravam dela a cidadania e gozo pleno dos seus direitos, sendo tuteladas e obrigadas a viverem entre os pares. Após a aprovação da Declaração Universal dos Direitos Humanos em 1948, na Assembleia Geral da ONU, os governos pactuaram ações voltadas à igualdade e democratização dos direitos sociais, essenciais ao gozo de uma vida digna, no qual por meio da Resolução 217-A(III) estabeleceram a proteção universal dos Direitos Humanos a todos os seres humanos: "Todos são iguais perante a lei e têm direito, sem qualquer restrição, a igual proteção da lei" (ONU, 1948, p. 2), ocasionando sinais de mudanças na luta pela igualdade de direitos para as pessoas com deficiências.

No final do século XX durante a Conferência Mundial sobre Educação para Todos, realizada em Jomtien (Tailândia), foi assinada a declaração que trata dos aspectos relacionados aos altos índices de crianças e jovens sem escolarização e, propõe aos Estados a necessidade de modificações nos sistemas de ensino, a fim de assegurar a inclusão e permanência de grupos socialmente excluídos (UNICEF, 1990). documento reafirma a Declaração Universal dos Direitos Humanos salvaguardando o direito à educação para todos, por meio de políticas de universalização do acesso, promoção da equidade, ambiente adequado à aprendizagem e, relembrando que a educação é um direito fundamental e dever a ser garantido pelos Estados (ONU, 1948). Para o Brasil, esta Declaração, mesmo não se tornando lei, trouxe um grande avanço com a elaboração do Plano Decenal de Educação para Todos (MEC, 1993), ao recomendar a implementação, no período de dez anos, de uma educação de qualidade para crianças, jovens e adultos.

Em 1994, ocorreu na Espanha a Conferência Mundial sobre Necessidades Educativas Especiais, a qual resultou na Declaração de Salamanca (UNESCO, 1994) que trata de princípios, políticas e práticas para pessoas com necessidades educativas especiais. Esta Declaração defende a inclusão de crianças, jovens e adultos com deficiência dentro do sistema regular de ensino. É considerado a primeiro documento orientador de políticas públicas a tratar da Educação Inclusiva, e nele a instituição destinada a educar, deve cumprir sua função social a todas as pessoas, acolhendo as diferenças e desenvolvendo a aprendizagem em respeito às necessidades individuais.

Apesar dos avanços propostos nesta década, a política governamental, fortemente influenciada por ideais neoliberais, assumiu uma postura de privatização da educação e reforçou o papel das instituições 
especializadas como espaço substitutivo à escola regular. Com isso a Política Nacional para Educação Especial (PNEE) de 1994 passa a endossar um conjunto de serviços a serem ofertados pelo Estado ao estudante com deficiência (BRASIL, 1994), muito deles na contramão da Educação Inclusiva. Sob a égide da integração, esta política determina que esses estudantes venham a frequentar diretamente ou indiretamente a sala de aula comum. Para tal, o MEC emite a Portaria $n^{\circ}$ I.793/I994 como medida para preparar os professores para esta nova realidade (MEC, 1994).

Em 2006, para assegurar às pessoas com deficiência os mesmos direitos que as demais pessoas é aprovada na ONU a Convenção Internacional sobre os Direitos das Pessoas com Deficiência, ratificada no Brasil com status de Emenda Constitucional, pelo Decreto n 6.949/2009. No Artigo 24, ao tratar do direito à educação, o Decreto determina que na formação docente deve ser incluído discussões acerca da luta e identidade da pessoa com deficiência, bem como métodos, técnicas e recursos de ensino, de forma a assegurar o direito de aprender desse estudante (BRASIL, 2009).

As políticas vigentes impulsionaram, no início do século XIX a expansão das matriculas em escolas regulares dos estudantes com deficiências e o Plano Nacional de Educação (PNE) - Lei n |3.005/20 I 4 (BRASIL, 20।4) passa a assegurar, na definição da política decenal para o país, o direito de aprender para o estudante com deficiência e a determinação de mudança nos cursos de formação de professores para atender à Inclusão:

4.16) incentivar a inclusão nos cursos de licenciatura e nos demais cursos de formação para profissionais da educação, inclusive em nível de pós-graduação, observado o disposto no caput do art. 207 da Constituição Federal, dos referenciais teóricos, das teorias de aprendizagem e dos processos de ensino-aprendizagem relacionados ao atendimento educacional de alunos com deficiência, transtornos globais do desenvolvimento e altas habilidades ou superdotação (BRASIL, 2014, p. 55)

Até o século $X X$ a formação docente necessária para ensinar ao estudante com deficiência, em sua grande maioria, ocorria nos cursos Normal e Pedagogia, que assumiam o papel de formar em um mesmo curso dois tipos de profissionais: o professor do ensino regular e os especialistas, entre eles o professor de Educação Especial. Este encaminhamento, de acordo com Bueno (1999), contribuiu para a determinação de que, no caso do ensino para pessoa com deficiência, seria uma escolha para poucos professores, especializados nas dificuldades e especificidades e com pouco conhecimento sobre o que é ser professor, ocasionando o insucesso da própria política de Inclusão Escolar. Diante do cenário de Inclusão Escolar, resultou no fato de que muitos professores de sala de aula comum não eram preparados para lecionar a esses estudantes. Destacamos aqui a atenção para a qualidade dos PPC que omitem este público da formação docente, desconsiderando que o quantitativo de estudantes com deficiências matriculados nos sistemas regulares de ensino.

Apesar dos avanços no aparato legal e histórico da luta das pessoas com deficiência, a maioria dos cursos de formação de professores desconhece a defesa por uma Educação Inclusiva e os documentos 
normativos que a amparam. Libâneo (1998) destaca que as reformas curriculares dos cursos de licenciaturas precisam estar alinhadas a política de educação inclusiva no país. O desafio não consiste na expansão do acesso da pessoa com deficiência à escola, mas está principalmente na violação do direito do estudante com deficiência de aprender, permanecer e participar do currículo escolar, e isso passa diretamente pelos PPC das licenciaturas.

Tal situação reforça a necessária urgência de revisão desses PPC no país, sustentando uma formação de caráter integral e interdisciplinar, que precisa contemplar conhecimentos de gestão de sistema educacional inclusivo, tendo em vista o desenvolvimento e aprendizagem do estudante com deficiência. O professor egresso das licenciaturas precisa aprender além dos conhecimentos gerais que permitam o exercício da docência, conhecimentos específicos acerca de como a pessoa com deficiência aprende, valorizando a Educação Inclusiva em atendimento as orientações da Resolução CNE/CEB n² 2/200 I:

São considerados professores capacitados para atuar em classes comuns com alunos que apresentam necessidades educacionais especiais aqueles que comprovem que, em sua formação, de nível médio ou superior, foram incluídos conteúdos sobre educação especial adequados ao desenvolvimento de competências e valores para: I - perceber as necessidades educacionais especiais dos alunos e valorizar a educação inclusiva; II - flexibilizar a ação pedagógica nas diferentes áreas de conhecimento de modo adequado às necessidades especiais de aprendizagem; III avaliar continuamente a eficácia do processo educativo para o atendimento de necessidades educacionais especiais; IV - atuar em equipe, inclusive com professores especializados em educação especial (MEC, 200 I , p.5)

Nessa diretriz, na perspectiva da Inclusão Escolar, o professor de sala de aula comum precisa aprender conhecimentos referentes à Educação Especial: as necessidades educacionais especiais dos estudantes com deficiências; os preceitos da Educação Inclusiva; assegurar na prática pedagógica a flexibilização curricular e uso de recursos de acessibilidade no processo educativo. A presença deste tipo de conhecimento no processo formativo de professores da Educação Básica pode ser conferido na Resolução CNE/CP n 2/20I5, a qual obriga as Instituições de Educação Superior (IES) a ajustarem os currículos dos cursos de licenciaturas inserindo conteúdos que possibilitem aos futuros professores a compreensão sobre as diversidades e as especificidades de cada estudante:

Art. 13 - $\S 2^{\circ}$ Os cursos de formação deverão garantir nos currículos conteúdos específicos da respectiva área de conhecimento ou interdisciplinares, seus fundamentos e metodologias, bem como conteúdos relacionados aos fundamentos da educação, formação na área de políticas públicas e gestão da educação, seus fundamentos e metodologias, direitos humanos, diversidades étnico-racial, de gênero, sexual, religiosa, de faixa geracional, Língua Brasileira de Sinais (Libras), educação especial e direitos educacionais de adolescentes e jovens em cumprimento de medidas socioeducativas (MEC, 2015, p. 12).

Para tal, a formação de professores precisa estar conectada às necessidades da educação básica, principalmente, na escolha dos conteúdos e do perfil de estudantes matriculados. No que se refere à organização curricular dos cursos de licenciatura o trabalho docente precisa estar pautado numa gama de 
competências e habilidades voltadas ao atendimento dos conhecimentos sobre crianças, adolescentes, jovens e adultos com e sem deficiência.

A formação inicial dos professores nos cursos de licenciatura, de acordo com Vitaliano (2008), deve preparar o futuro professor para compreender e assegurar o processo de inclusão escolar. Cabe ao professor a tarefa de garantir a permanência e aprendizagem dos estudantes com deficiência, entendendo suas necessidades e compreendendo suas especificidades, sem deixar de contemplar os demais estudantes da sala de aula.

Na vertente de formação docente para uma Educação Inclusiva a aprovação da Lei n $10.436 / 2002$ (BRASIL, 2002), regulamentada pelo Decreto no 5.626/2005 (BRASIL, 2005), determina que a Língua Brasileira de Sinais (Libras) passa a ser conteúdo curricular obrigatório dos cursos de formação de professores e profissionais da educação para o exercício do Magistério, em níveis médio e superior, e do curso de Fonoaudiologia. O componente curricular Libras, considerada um importante passo no movimento de inclusão educacional extrapola o campo de disciplina obrigatória e ganha status de curso de formação de professores.

A criação da licenciatura Letras: Libras/Língua Portuguesa vem para suprir a lacuna da formação de professores para o ensino de Libras nos anos finais no Ensino Fundamental, no Ensino Médio e na Educação Superior. Entretanto, para suprir a formação de professores para o ensino de Libras na Educação Infantil e anos iniciais do Ensino Fundamental é recomendada nos cursos de Pedagogia ou Curso Normal Superior a formação bilingue, na qual Libras e Língua Portuguesa escrita se constituam línguas de instrução. A inclusão da disciplina de Libras ou a oferta de cursos de formação em nível de ensino superior é vista como uma ação fundamental para a melhoria da formação docente, proporcionando a compreensão dos estudantes surdos e uma interação mais efetiva em sala de aula.

Com a aprovação da Lei n 13. I46/20। 5, o artigo 28 determina que o poder público assegure, crie, desenvolva, implemente, incentive, acompanhe e avalie a "inclusão em conteúdos curriculares, em cursos de nível superior e de educação profissional técnica e tecnológica, de temas relacionados à pessoa com deficiência nos respectivos campos de conhecimento" (BRASIL, 20I5, p. 4). Tal determinação, de acordo com a Resolução CNE/CP n 2/20 I 5, deve estar prevista nos PPC e Planos de Desenvolvimento Institucional (PDI) das IES:

Art. $4^{\circ} \mathrm{A}$ instituição de educação superior que ministra programas e cursos de formação inicial e continuada ao magistério, respeitada sua organização acadêmica, deverá contemplar, em sua dinâmica e estrutura, a articulação entre ensino, pesquisa e extensão para garantir efetivo padrão de qualidade acadêmica na formação oferecida, em consonância com o Plano de Desenvolvimento Institucional (PDI), o Projeto Pedagógico Institucional (PPI) e o Projeto Pedagógico de Curso (PPC) (MEC,20 I5, p. 5)

Os PPC devem estar adequados para assegurar uma formação completa aos seus estudantes, nos quais os processos formativos se respaldam na multiplicidade de conhecimentos teóricos e práticos que 
resulte do PPC e do percurso formativo articulado com a realidade posta. Entretanto, somente a reformulação dos currículos não é suficiente e as IES precisam estar atentas a formação contínua de seu corpo docente, revisando não apenas os currículos, como também concepções e métodos de ensino e procedimentos avaliativos.

\section{METODOLOGIA}

O estudo que originou este artigo envolveu pesquisa qualitativa de cunho exploratório, por meio de pesquisa documental nos PPC de licenciatura da UFAL, Campus A.C. Simões, Maceió-Alagoas. Além da pesquisa bibliográfica de estudos na área (CHICON, 200I; VTALIANO, 2008; VITALIANO; DALL'ACQUA, 2012), foram analisados leis, decretos e portarias referentes ao processo de inclusão dos estudantes com deficiência na Educação Básica.

A análise documental auxiliou o estudo complementando informações obtidas durante a pesquisa bibliográfica, desvelando aspectos novos da temática (LUDKE; ANDRÉ, 1986). Trouxe subsídios à identificação, nos PPC, de extratos de textos que sinalizavam ou contemplavam a indicação da preparação para Inclusão Escolar no processo de formação docente. Os PPC analisados não somente representam evidências e visões da realidade, como também se destinam a desvelar a presença de aspectos significativos para o estudo.

Os PPC das licenciaturas analisados neste estudo foram catalogados, através da lista de cursos disponíveis na Pró-reitora de Graduação (PROGRAD) da UFAL e exportado do site www.ufal.edu.br, na aba da PROGRAD, Cursos de Graduação, Projetos Pedagógicos, Campus A.C. Simões. Nesta aba foram identificados 58 (cinquenta e oito) Cursos de Graduação, destes 17 (dezessete) correspondem a Cursos de licenciatura presencial, conforme lista enviada pela PROGRAD.

Na leitura e seleção destes PPC de licenciatura, foi adotada a técnica de análise das matrizes curriculares e ementários dos componentes curriculares relacionados à temática Educação Especial, Educação Inclusiva e Diversidade, Educação Física Adaptada ou Libras que, de acordo com as normativas legais, estão diretamente relacionadas ao ensino e aprendizagem da pessoa com deficiência e ao processo de inclusão escolar. O PPC Letras Líbras/Língua Portuguesa não foi analisado pela sua natureza peculiar de formação e público alvo.

A Tabela I demonstra a realidade formativa dos PPC de Licenciaturas da UFAL no que se refere a formação docente para inclusão escolar, o período que esses componentes curriculares são ministrados, a carga horária e a natureza do componente curricular obrigatório ou eletivo. 
Tabela I - Licenciaturas com componentes curriculares obrigatórios e eletivas relacionadas à Educação Especial.

\begin{tabular}{|c|c|c|c|c|}
\hline CURSO & ANO DO PPC & DISCIPLINA & PERÍODO & $\mathrm{CH}$ \\
\hline & 2006 & Educação Especial (obrigatória) & 40 & 40 horas \\
\hline PEDAGOGIA & & Libras (obrigatória) & 80 & 60 horas \\
\hline \multirow{6}{*}{ EDUCAÇÃO FÍSICA } & \multirow{6}{*}{2006} & $\begin{array}{l}\text { Metodologia do Ensino dos } \\
\text { Jogos e Brincadeiras na } \\
\text { Educação Física (obrigatória) }\end{array}$ & 30 & 80 horas \\
\hline & & $\begin{array}{l}\text { Metodologia do Ensino das } \\
\text { Atividades Físicas Adaptadas } \\
\text { (obrigatória) }\end{array}$ & 50 & 60 horas \\
\hline & & $\begin{array}{l}\text { Educação Física Adaptada } \\
\text { (obrigatória) }\end{array}$ & 50 & 40 horas \\
\hline & & $\begin{array}{l}\text { Projetos Integradores V } \\
\text { (obrigatória) }\end{array}$ & 50 & 40 horas \\
\hline & & Libras (obrigatória) & 70 & 60 horas \\
\hline & & $\begin{array}{l}\text { Tópicos Avançados em Atividade } \\
\text { Física Adaptada (eletiva) }\end{array}$ & Não define & 40 horas \\
\hline MATEMÁTICA & 2006 & Libras (obrigatória) & 80 & 60 horas \\
\hline MÚSICA & 2006 & Educação Especial (eletiva) & Não define & 40 horas \\
\hline \multirow[t]{2}{*}{ QUIMICA } & \multirow[t]{2}{*}{2007} & & 70 & 60 horas \\
\hline & & Educação Especial (eletiva) & Não define & 40 horas \\
\hline HISTÓRIA & 2015 & Libras (obrigatória) & 70 & 60 horas \\
\hline \multirow[t]{2}{*}{ DANÇA } & \multirow[t]{2}{*}{2016} & $\begin{array}{l}\text { Dança com Corpos } \\
\text { Diferenciados (obrigatória) }\end{array}$ & 60 & 60 horas \\
\hline & & Libras (obrigatória) & 70 & 60 horas \\
\hline $\begin{array}{l}\text { LETRAS/ } \\
\text { FRANCÊS }\end{array}$ & 2016 & $\begin{array}{l}\text { Fundamentos de Libras } \\
\text { (obrigatória) }\end{array}$ & 3 & 60 horas \\
\hline \multirow[t]{3}{*}{ CIÊNCIAS SOCIAS } & \multirow[t]{3}{*}{2018} & Libras (obrigatória) & 50 & 54 horas \\
\hline & & $\begin{array}{l}\text { Educação e } \\
\text { (obrigatória) }\end{array}$ & 30 & 72 horas \\
\hline & & Educação Especial (eletiva) & Não define & 54 horas \\
\hline \multirow[t]{3}{*}{ LETRAS/ INGLÊS } & \multirow[t]{3}{*}{2018} & \multirow{2}{*}{$\begin{array}{l}\text { Fundamentos de Libras } \\
\text { (Obrigatória) } \\
\text { Questões Contemporâneas em } \\
\text { Linguística Aplicada (obrigatória) }\end{array}$} & 3은 & 72 horas \\
\hline & & & 50 & 72 horas \\
\hline & & $\begin{array}{lll}\text { Estudos do } & \text { Discurso } \\
\text { (obrigatória) } & & \end{array}$ & 70 & 72 horas \\
\hline $\begin{array}{c}\text { LETRAS/ } \\
\text { PORTUGUÊS }\end{array}$ & 2019 & $\begin{array}{l}\text { Fundamentos de Libras } \\
\text { (obrigatória) }\end{array}$ & 50 & 72 horas \\
\hline $\begin{array}{l}\text { LETRAS/ } \\
\text { ESPANHOL }\end{array}$ & 2019 & $\begin{array}{l}\text { Fundamentos de Libras } \\
\text { (obrigatória) }\end{array}$ & 50 & 72 horas \\
\hline \multirow[t]{2}{*}{ FISICA } & \multirow[t]{2}{*}{2019} & Libras (obrigatória) & 50 & 54 horas \\
\hline & & $\begin{array}{l}\text { Materiais sobre Física em Áudio } \\
\text { e em Braile para Deficientes } \\
\text { Visuais (Atividades Curriculares } \\
\text { de Extensão) }\end{array}$ & Não define & $\begin{array}{l}\text { Não } \\
\text { define }\end{array}$ \\
\hline TEATRO & 2019 & Libras (obrigatória) & 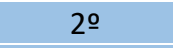 & 54 horas \\
\hline & & $\begin{array}{l}\text { Ensino da Arte Educação para } \\
\text { Pessoas com Deficiência } \\
\text { (eletiva) }\end{array}$ & Não define & 54 horas \\
\hline & 2019 & Libras (obrigatória) & 2은 & 54 horas \\
\hline
\end{tabular}

Fonte: elaboração das autoras (20|8). 
No panorama de Cursos de Licenciatura presencial da UFAL, a Tabela I indica que os PPC correspondem aos anos de 2006 a 2019, metade foram elaborados visando atender a Resolução CNE/CP n² 2/20I5 (MEC, 20I5) e, quase todos atendem a Lei n 10.436/2002 (BRASIL, 2002).

\section{RESULTADOS E DISCUSSÕES}

O PPC de licenciatura em Pedagogia aponta o aumento de crianças e jovens com deficiências na Educação Básica, por meio do número de matrículas da Educação Especial no Ensino Fundamental no período de 2003 a 201 I, assegurando conteúdos e atividades que consistam na formação de pedagogos com "capacidade para atuar com portadores de necessidades especiais, em diferentes níveis da organização escolar, de modo a assegurar seus direitos de cidadania" (UFAL, 2006a, p. 26). Para tal, estabelece no Eixo Estruturante do curso, campo e bases da ação, dois componentes curriculares direcionados para o ensino da pessoa com deficiência: Educação Especial e Libras.

A ementa do primeiro componente curricular busca estudar o "desenvolvimento atípico das crianças e adolescentes, compreendendo os recursos educacionais disponíveis na comunidade, os programas de prevenção e assistência existentes, trabalhando o educando na perspectiva do processo de inclusão social" (UFAL, 2006a, p. 57) O componente curricular procura, de forma geral, retratar a educação para pessoas com deficiência considerando a inclusão escolar, práticas, programas e projetos desenvolvidos com este público. Essa situação corrobora com o pensamento de Vitaliano (2002, p. 290) ao afirmar que os PPC devem:

[...] prover conhecimentos que venham a suprir as necessidades objetivas e subjetivas do professor. Os professores precisam ser formados com conhecimentos que os habilitem a lidar com as necessidades especiais de seus alunos, assim como a lidar com os sentimentos, crenças e expectativas que esses alunos despertam neles. Além disso, devem também aprender a lidar com os sentimentos e reações negativas que seus alunos 'normais' podem apresentar perante os especiais e aprender a conciliar as relações entre eles, para que desenvolvam aprendizagens sociais e acadêmicas.

Esse pensamento deixa claro que o processo de formação dos professores precisa prever conteúdos e práticas que deem conta do processo ensino e aprendizagem dos estudantes com deficiência em sala de aula comum, na tentativa de valorizar a ação pedagógica e as interações sociais como agentes de desenvolvimento e aprendizagem.

O segundo componente curricular analisado foi Libras, ofertado pela Faculdade de Letras (FALE) em atendimento ao disposto no Artigo $3^{\circ}$ do Decreto n 5.626/2005, voltado ao estudo da Língua e a importância do seu papel para a comunidade surda. Apesar da temática estar diretamente ligada à pessoa com deficiência, o conteúdo abordado ao longo do componente curricular se encontra distante da realidade vivenciada na Educação Básica, ou seja, não instrumentaliza o licenciando a ensinar na Educação 
Básica, utilizando a Libras em ambiente escolar inclusivo. Esse fato constituí um problema, pois mesmo reconhecendo que a Educação Básica tem vivenciado um aumento de matrículas dos estudantes com deficiências na escola regular o PPC, apesar de incluir a Libras como componente curricular, não menciona que práticas pedagógicas podem ser desenvolvidas com estudantes surdos em sala de aula comum.

O PPC de licenciatura em Educação Física apresenta três componentes curriculares que preparam o professor para atuar com estudantes com deficiência, sendo dois de natureza obrigatórias e uma eletiva. O primeiro componente é Metodologia do Ensino das Atividades Físicas, aparecendo ao longo do PPC como uma releitura de Educação Física Adaptada, cuja ementa estabelece:

Atividade Física Adaptada. Análise da realidade das pessoas portadoras de necessidades especiais: aspectos históricos, legais, filosóficos e político-sociais. Principais tipos de deficiências e suas características: física, auditiva, mental e visual. Programas e metodologias de ensino adaptados às atividades físico esportivas para pessoas portadoras de necessidades especiais. Experiências de prática de ensino (UFAL, 2006b, p. 33)

C componente curricular trabalha de modo geral as necessidades especiais das pessoas com deficiências. De acordo com Alves e Duarte (20|4), a inclusão só se torna possível a partir de três elementos essenciais que agem de maneira complementar: a adequação do contexto (estrutural, pedagógica, metodológica e material); a participação social (condicionada à aceitação pelo grupo de estudantes) e; a capacidade (o estudante com deficiência sentir-se capaz de desempenhar as atividades). Para tal, estudos voltados à Atividades Físicas Adaptadas têm ocupado mais espaços nos PPC de licenciatura em Educação Física nos últimos anos.

O segundo componente curricular obrigatório é Libras que tem a natureza e ementa idêntica ao PPC de licenciatura em Pedagogia, compreendendo a cultura surda e os aspectos históricos e linguísticos da Libras.

No bojo dos componentes curriculares não-obrigatórios vemos Tópicos Avançados em Atividade Física Adaptada, cujo objetivo é aprofundar temáticas abordadas no componente curricular Atividade Física Adaptada, a partir dos interesses dominantes levantados por professor e estudantes em função da dinâmica do conhecimento e do mercado de trabalho, utilizando a metodologia de estudos de casos e sem bibliografia básica estabelecida a priori. O estudo de caso envolve dinâmicas e levantamento de interesses a partir de consulta direta juntos aos grupos interessados, sendo a ementa e o programa desenvolvidos e arquivados conforme a oferta em cada semestre. Esse componente curricular, de forma geral, trabalha com todas as especificidades encontradas na Educação Especial, em prol de uma melhoria na qualidade da formação docente:

Buscando atender às orientações do MEC para a educação infantil, ensino fundamental e médio, prescritas nas Diretrizes Curriculares Nacionais, o CEDU propõe formar um profissional da educação capaz de atender, a partir de uma sólida e ampla formação cultural, dentro do âmbito específico de sua área de atuação, aos objetivos dos diferentes níveis de ensino e às características do desenvolvimento psicomotor e afetivo do educando, incluindo em sua formação 
conhecimentos relativos à educação de alunos com necessidades especiais, educação de jovens e adultos e comunidades indígenas (UFAL, 2006b, p. 12).

Nos componentes curriculares previstos no PPC de licenciatura em Educação Física constatamos que alguns mesmo não tratando diretamente das pessoas com deficiência, as consideram no corpus do componente curricular como exemplo: Metodologia de Ensino nos Jogos e Brincadeiras na Educação Física, integrante do núcleo de práticas pedagógicas ofertado no $3^{\circ}$ período do curso, que busca envolvimento indireto com a Educação Especial ao valorizar à inclusão social, abrangendo seu alcance de visão para todas as áreas possíveis. A ementa retrata a estrutura, natureza e significados do jogo na distinção e relações com o esporte, considera o ensino e a prática dos jogos e brincadeiras voltados às diferentes populações, entre elas pessoas com deficiências. $\bigcirc$ componente curricular Projetos Integradores $\vee$ está voltado ao desenvolvimento de atividades interdisciplinares que ressaltem as adaptações da prescrição de atividades físicas para essas pessoas.

O PPC de licenciatura em Matemática apresenta apenas um componente curricular voltado à pessoa com deficiência: Libras, ofertado no último período do curso, sendo obrigatório (UFAL, 2006c). Apesar de aparecer como eletivo em uma parte do texto, a ementa e a bibliografia a ser trabalhada não consta no ementário.

No PPC de licenciatura em Música, o componente curricular Educação Especial não é obrigatório (UFAL, 2006d) e depende da demanda de professores pelo Centro de Educação (CEDU). Sem ementa, bibliografia e carga horária descrita no PPC, a oferta durante o curso pode não ocorrer, caso não haja disponibilidade de professores para assegurar aos licenciados em Música uma formação docente voltada para o ensino das pessoas com deficiência. Ao contrário dos demais PPC analisados, não há oferta do componente curricular Libras, desrespeitando a legislação em vigor.

No caso do PPC de licenciatura em Química aparecem dois componentes curriculares: Libras e Educação Especial (UFAL, 2007). O primeiro tem oferta obrigatória e aparece no penúltimo período do curso com ementa relacionada ao "estudo da Língua Brasileira de Sinais (LIBRAS), da sua estrutura gramatical, de expressões manuais, gestuais e do seu papel para a comunidade surda" (UFAL, 2007, p. 43). Este componente curricular está voltado apenas para a compreensão pelo estudante da Libras, sem a preocupação de como este conhecimento deve ajudar o futuro professor na sua atuação pedagógica. $\bigcirc$ componente curricular Educação Especial não é obrigatório e a ementa contempla o estudo do desenvolvimento atípico, o uso de recursos educacionais especiais e os programas de prevenção e assistência existentes. Esta ementa não aparece na íntegra no PPC, mas se trata de uma cópia do PPC de licenciatura em Pedagogia, isto porque o envio do professor para ministrar o componente curricular depende da disponibilidade no quadro de professores do CEDU para atender as demandas do curso. 
No PPC de licenciatura em História o único componente curricular voltado a temática da pessoa com deficiência é Libras (UFAL, 20 I5), ofertado pela FALE, com natureza obrigatória e ementa destinada a conceituação, histórico da Língua e discussão sobre a comunidade surda.

No PPC de licenciatura em Dança foi sugerido pelas Diretrizes Curriculares Nacionais do Curso de Graduação em Dança - Resolução CNE/CES n 3/2004 (MEC, 2004) a criação de um componente curricular voltado à "Dança para Portadores de Necessidades Especiais" (UFAL, 20 I6a, p. I4) visa discutir questões relacionadas a escola e educação inclusiva, contudo esta demanda não chegou a ser cumprida. Neste curso está previsto, como um dos itens relacionados ao perfil do egresso, a formação de um professor que ensina estudantes com deficiências em ambiente educacional inclusivo, conforme previsto na Resolução CNE/CES n³/2004 (BRASIL, 2004). Na ementa do componente curricular Dança com Corpos Diferenciados, também, constatamos um possível atendimento a Resolução supracitada, uma vez que na própria ementa está descrito o:

Contexto histórico das transformaç̧̃es no pensamento e nas relações da sociedade com pessoas com corpos diferenciados. A Declaração Universal dos Direitos Humanos e os Marcos normativos da educação especial. Educação inclusiva e a relação do professor com alunos com corpos diferenciados. Metodologias de Educação Especial ou Educação Inclusiva aplicadas ao ensino da dança para pessoas com corpos diferenciados. A produção, em dança, de artistas com corpos diferenciados. (UFAL, 2016a, p. 91-92)

mesmo componente curricular, pelo teor da discussão, pode ser visto como uma tentativa de atender o disposto no Artigo $2^{\circ}$ da Resolução CNE/CP n 2/20I 5 (MEC, 20 I 5), considerando que o PPC está relacionado à formação de professores para o exercício da docência na Educação Básica e nas diversas modalidade, entre elas a Educação Especial, de forma específica e/ou interdisciplinar. Libras se constitui como componente curricular obrigatório, possibilitando aos estudantes que optarem em realizar suas práticas de Estágio Supervisionado em escolas e/ou instituições que atendam a pessoas surdas, como suporte básico para a comunicação.

No PPC de licenciatura em Letras/Francês, o único componente curricular disposto no PPC é Fundamentos de Libras, cuja ementa descreve o "estudo dos fundamentos da Língua Brasileira de Sinais (Libras), com noções práticas de sinais e interpretação, destinado às práticas pedagógicas na educação inclusiva" (UFAL, 20 I 6b, p. 38). O componente curricular compõe o núcleo de formação para a docência destinada a reflexão das práticas pedagógicas desenvolvidas em ambiente educacional inclusivo, ainda que diretamente relacionada apenas à Educação dos Surdos, como demonstra nos Anexos ao incluir o Decreto $n^{\circ} 5.626 / 2005$ (BRASIL, 2005).

O PPC de licenciatura em Ciências Sociais apresenta no componente curricular Libras (UFAL, 20I8b), ofertado também pela FALE, na mesma perspectiva apresentada no PPC de licenciatura em Letras/Francês (UFAL, 20I6b). Além disso, a discussão das pessoas com deficiência também está prevista nos componentes curriculares: Educação e Diversidade, de oferta obrigatória (UFAL, 20 | 8b), que aborda 
entre as múltiplas facetas da educação a da pessoa com deficiência; e, Educação Especial, considerado nãoobrigatório, ofertada pelo CEDU com a mesma ementa apresentada em outros PPC analisados.

O PPC de licenciatura em Letras/Inglês esclarece estar adequado a Resolução CNE/CP n 2/20 I 5 e a Resolução Consuni/UFAL n 6/2018², assegurando como obrigatório o componente curricular Fundamentos de Libras (UFAL, 2019a), nos mesmos moldes dos PPC das licenciaturas em Letras/Francês (UFAL, 2016b) e em Letras/Espanhol (UFAL, 20।9b). Destaca ainda que, ao longo do curso, vários componentes curriculares irão contemplar discussões relacionadas às pessoas com deficiência, entre eles: Estudos do Discurso, Questões Contemporâneas em Linguística Aplicada, Ensino de Língua Inglesa e Ensino-aprendizagem de Língua Inglesa, podendo ainda ser contempladas nos componentes curriculares: Linguística Aplicada e Ensino de Línguas Estrangeiras, Elaboração de Material Didático, Letramentos e Perspectivas Críticas, entre outras. Ao analisarmos a ementa dos componentes curriculares supracitados, constatamos a existência de menção direta a esta temática no componente curricular Estudos do Discurso:

Introdução a princípios teóricos e metodológicos da análise do discurso aplicados a diferentes gêneros discursivos escritos e orais, partindo de abordagens diversas, relacionando-os aos estudos interdisciplinares sobre educação, cultura, identidade, ideologia, gênero, sexualidade, questões étnico-raciais e relacionadas aos estudos da deficiência (UFAL, 20 I 8c, p. 109)

O conteúdo relacionado ao Estudo da Deficiência está presente também na ementa dos componentes curriculares: Questões Contemporâneas em Linguística Aplicada e Ensino de Língua Inglesa, apresentando uma bibliografia sobre a área mais completa. Nos demais componentes curriculares citados, não há menção sobre temas relacionados às pessoas com deficiências.

No PPC de licenciatura em Letras/Espanhol além de não haver nenhum componente curricular voltado à pessoa com deficiência, exceto Libras como citado anteriormente, chama a atenção o componente curricular Didática do Ensino da Língua Espanhola, ofertado de forma obrigatória no $6^{\circ}$ período perfazendo um total de 90 horas, com ênfase no "aprimoramento do fazer pedagógico no que diz respeito ao ensino das quatro habilidades (ler, escrever, ouvir e falar), intermediado por práticas letradas voltadas para a formação do cidadão crítico" (UFAL, 2019b, p. 60). A ementa desconsidera as várias formas de comunicação utilizadas quando se tem estudantes com deficiência, tanto nas aulas de graduação; quanto nas salas de aula de Educação Básica.

No caso do PPC de licenciatura em Letras/Língua Portuguesa o único componente curricular relacionado à formação do licenciado para o ensino da pessoa com deficiência é Fundamentos da Libras, ofertado de forma obrigatória durante o $5^{\circ}$ período com carga horaria de 72 horas (UFAL, 2019a). No

\footnotetext{
${ }^{2} A$ Resolução Consuni/UFAL n 6/20 8 define os componentes curriculares comuns aos cursos de graduação de formação de professores para a Educação Básica (UFAL, 20 I8a). Nela ficou estabelecido que a disciplina de Libras com carga horária de 54 horas está sob a responsabilidade do Curso de Letras ou Letras/Libras e deve ser ofertada até o $5^{\circ}$ período. Outras disciplinas que contemplem os pressupostos da formação docente, como conteúdos relacionados aos fundamentos da Educação Especial, Direitos Humanos, entre outras, devem ser ofertadas entre o $2^{\circ}$ e $7^{\circ}$ períodos.
} 
corpus do documento o ensino de Libras é visto como componente curricular voltado à formação do licenciado acerca da acessibilidade das pessoas surdas, chamando a atenção para o atendimento às necessidades de interação linguístico-discursiva, além da inserção do estudante surdo em sala de aula comum. Nesse sentido, a ementa contempla o panorama histórico, metodológico, competências e habilidades necessárias ao desempenho comunicativo nos processos de interação e inclusão dos surdos e surdocegos no sistema educacional.

No PPC de licenciatura em Física não há menção a nenhum componente curricular voltado à formação de professores em contexto de Inclusão Escolar, apesar de ter um tópico relacionado a "Outras Temáticas Abordadas no Curso: Acessibilidade e Transtorno do Espectro Autista" (UFAL, 20I 9c, p. 4I). Nesse tópico não é apresentado como o assunto deve ser abordado no processo formativo de futuros professores da Educação Básica; nem sua relação com outros componentes curriculares; ou até mesmo, como este conhecimento deve fazer parte da prática pedagógica do professor de Física. O PPC ao tratar de estudantes com deficiências apresenta apenas as ações do Núcleo de Acessibilidade (NAC) da UFAL no atendimento aos estudantes público alvo da Educação Especial.

De acordo com Pedroso, Campos e Duarte (2013, p. 42) "não existem caminhos prontos a serem seguidos. Ainda é necessário que sejam produzidos conhecimentos sobre as práticas pedagógicas em contextos inclusivos a partir das contribuições das pesquisas na área da Educação Especial, da Pedagogia e da Didática". Com isso, aproximar-se da escola e adentrar na sala de aula permite ao licenciando conhecer como o ensino vem sendo realizado em tempos de Inclusão Escolar. O curso de Física até se aproxima deste pensamento, quando estabelece no PPC uma discussão voltada à produção de material didático para o ensino da Física aos estudantes com deficiência. Ao contemplar a Inclusão Escolar nas Atividades Curriculares de Extensão (ACE), o PPC vislumbra o projeto Materiais sobre Física em Áudio e em Braile para Deficientes Visuais, com a possibilidade de tornar-se componente curricular a ser desenvolvido no meio ou final do curso.

\footnotetext{
Nesse projeto materiais em áudio e em braile são/foram desenvolvidos no Instituto de Física da UFAL, campus Maceió. Ele tem como público alvo os deficientes visuais do estado de Alagoas. O material produzido foi distribuído para todas aquelas escolas que tiverem interesse em utilizar o material como um suporte didático, bem como será disponibilizado diretamente para os alunos com deficiência visual que tenham interesse em adquirir o material. Este trabalho é muito importante para o nosso estado de Alagoas, uma vez que ações pedagógicas para ensinar Física para pessoas com alguma dificuldade especial são praticamente inexistentes e sabemos que é urgente a necessidade de tais iniciativas para proporcionar cada vez mais a inclusão dos deficientes visuais nas diversas áreas do saber e da sociedade. (UFAL, 2019c, p. 38-39)
}

A proposta de ACE é uma inovação na UFAL, sendo estabelecida pela Resolução Consuni/UFAL $n^{\circ}$ 6/20I8 (UFAL, 2018a) com a finalidade de aproximar, de forma interdisciplinar, educativa, cultural, cientifica ou política, a UFAL de outros setores da sociedade. Torna as ações de extensão componente curricular obrigatório, determinando que 10\% (dez por cento) da carga horária do curso seja destinado a 
projetos, eventos, mostras e cursos apresentados à comunidade. O curso de Física busca provocar o diálogo entre jovens estudantes e professores do Ensino Médio, com o intuito de suprir os espaços não preenchidos com os conteúdos programáticos de Física, desenvolvidos nas escolas de Educação Básica, sempre considerando as demandas sociais do Estado. $O$ componente curricular Libras consta no eixo ênfase político-pedagógica, com oferta de natureza obrigatória e com programação e professores lotados na FALE, voltado à compreensão da cultura surda e o ensino aos estudantes surdos.

Assim como o PPC de licenciatura em Física (UFAL, 2019c), o de Teatro também traz a discussão da Acessibilidade pela análise das condições de acessibilidade arquitetônica e pela atuação do NAC, movimento semelhante aparece em todos os PPC publicados a partir de 2018. Há um componente curricular voltado à preparação do professor para o ensino do estudante com deficiência: o Ensino de Arte para Pessoas com Deficiência, de natureza não-obrigatória, a oferta depende da disponibilidade de professor, podendo ser ofertado ou não ao longo do curso:

\begin{abstract}
Introdução aos aspectos característicos e de desenvolvimento de diferentes tipos de deficiência, compreendendo as políticas públicas, a legislação brasileira, a tecnologia assistiva e os diversos recursos de acessibilidade educacional no ensino da Arte para pessoas com deficiência. Estudo da Educação inclusiva: fundamentos e paradigmas como campo de saber sobre as alteridades da pessoa com deficiência, refletindo acerca da docência artística-educacional. Ensino e práticas corporais voltados às pessoas com deficiência, com vistas à construção de uma pedagógica da Arte, especialmente nas Artes Cênicas, favorecedora do acesso, permanência e sucesso do aluno com deficiência, sustentada em princípios éticos e na aceitação da pluralidade humana, em seus aspectos singulares, sociais e culturais (UFAL, 2019d, p. 144-|45)
\end{abstract}

Como isso, um componente curricular inovador com a finalidade de discutir as questões relacionadas à escola inclusiva e Educação Inclusiva é relegada a possibilidade de ser ofertada ou não, além de aparecer em outros momentos do PPC, como mecanismo de garantir a transdisciplinaridade junto a outros componentes curriculares e, aliado a discussão da Educação de Direitos Humanos. $\bigcirc$ componente curricular Libras é de oferta obrigatória, com a finalidade de dar suporte aos estudantes, principalmente, durante as ações de Estágio Supervisionado em escolas e/ou instituições que atendem pessoas surdas. É um componente curricular que visa despertar no licenciando a importância da utilização desta língua em espetáculos teatrais, produzidos ao longo do curso.

No PPC de licenciatura Geografia foi constatado que a oferta obrigatória do componente curricular Libras se propõe a assegurar que os licenciandos também possam realizar suas práticas de Estágio Supervisionado em escolas e/ou instituições que atendam pessoas surdas, recebendo no curso suporte básico à comunicação com essas pessoas. A ementa trata dos "Aspectos linguísticos e culturais da Língua Brasileira de Sinais (LIBRAS) e da comunidade surda. Histórico da surdez no Brasil e no mundo" (UFAL, 2019e, p. 54) em atendimento a Resolução CNE/CP n²/2015. Os componentes curriculares obrigatórios Estágio Supervisionado I, II, III e IV ao atender essa Resolução determina que durante a vivência no espaço escolar do Ensino Fundamental o licenciando realize: 
Observação participante nas escolas acerca do ensino de Geografia nesta modalidade de ensino. Observar a organização escolar e o sistema educativo através dos programas que poderão estar presentes na escola como: educação infantil, educação especial, educação à distância e educação de jovens e adultos - EJA e outros (UFAL, 2019e, p. 96-97)

Dos PPC analisados, o de licenciatura em Geografia é um dos poucos que prevê na formação prática do licenciado, via Estágio Supervisionado, a discussão da Inclusão Escolar. Isto significa que o curso precisará ao longo dos componentes curriculares teóricos abordar conteúdos referentes à Inclusão Escolar, Metodologias e Recursos de Acessibilidade, assim como Flexibilização Curricular. Aspectos não observado durante a análise das demais ementas do curso, principalmente, nos componentes curriculares que antecedem os Estágios Supervisionados.

O PPC de licenciatura em Ciências Biológicas traz o componente curricular Libras, voltado ao estudo da Língua contemplando os aspectos gramaticais, expressões não manuais, o sujeito surdo, a cultura e identidade surdas (UFAL, 20 19f). O componente curricular Estágio Supervisionado II ao tratar de ações voltadas a observação no espaço escolar, como mapeamento e diagnóstico da educação escolar, prevê visita e ações interventivas às escolas e instituições de Ensino Fundamental e Médio, Educação de Jovens, Adultos e Idosos, e Educação Especial, com atenção especial ao ensino de Ciências e/ou de Biologia. $\bigcirc$ papel do Estágio está ligado a observação, reflexão e transformação de práticas escolares, a partir de um processo de escuta e observação, compreendendo que as atividades de estágio visam promover a formação de um professor reflexivo e pesquisador (PIMENTA; LIMA, 20I2). Contudo, destacamos o mesmo aspecto observado no PPC de licenciatura em Geografia (UFAL, 20/9e), com relação ao componente curricular Estágio Supervisionado, pelo fato de não existir nenhuma discussão teórica que subsidie o licenciado no campo de estágio para atuar em salas de inclusão escolar.

\section{CONSIDERAÇÕES FINAIS}

A Educação Especial é uma modalidade de ensino composta de um conjunto de serviços, recursos e profissionais de apoio à Inclusão Escolar, destinada às pessoas com deficiências, TGD e altas habilidades/superdotação. Essa modalidade visa assegurar o direito à Educação para um público específico que, por motivos diversos, foi excluído e negligenciado do acesso ao currículo escolar. Essa modalidade de ensino não se define pelo turno ou espaço que é oferecido, mas pela sua finalidade e prática pedagógica com vista a atender as necessidades e especificidades dos estudantes com deficiência.

Nesse sentido, os PPC de licenciatura da UFAL precisam garantir um processo formativo no qual o licenciado se apropria dos conhecimentos relacionados à pessoa com deficiência, valorização da ação pedagógica e interações sociais, a partir do conjunto de saberes trabalhados ao longo do curso de formação. 
Os resultados encontrados nas análises dos 16 (dezesseis) PPC de licenciatura Campus A.C. Simões da UFAL, desvelam a política de formação de professores da UFAL. Em nenhum dos PPC analisados foi constatado o atendimento à Portaria MEC n I.793/I994 (MEC, 1994), entendendo que esta constitui apenas numa recomendação e não, numa obrigação dos PPC. Este fato em comparação com o atendimento à Lei n 10.436/2002 (BRASIL, 2002) e ao Decreto n 5.626/2008 (BRASIL, 2008) demonstrou que na maioria dos PPC analisados o componente curricular Libras tem natureza obrigatória, estando presente em quase todos os programas curriculares. Na análise das ementas percebemos que quase não há variedade na forma como o componente curricular é concebido em cada PPC de licenciatura, independente do período de publicação.

O componente curricular Educação Especial foi encontrado em 4 (quatro) PPC de licenciatura, sendo que em 3 (três) desses têm natureza eletiva, ofertado pelo CEDU. Com a publicação da Resolução Consuni/UFAL n 6/2018 (UFAL, 2018) a Educação Especial saiu do rol dos componentes curriculares ofertados pelo CEDU às demais licenciaturas, cabendo a cada Curso definir a melhor maneira de atender a Resolução CNE/CP n 2/20 I 5 (MEC, 20 I 5). Esta situação apontou medidas diferenciadas em cada PPC, por exemplo: em Letras e História não há menção a formação docente para atuar junto a estudantes com deficiência; em Física e Teatro foram pensadas em componentes curriculares eletivos para discutir práticas ou recursos para esse público; no caso de Letras/Inglês a discussão da temática passa por dois componentes curriculares obrigatórios: Geografia e Ciências Biológicas preveem nas ações de Estágio Supervisionado a única oportunidade durante todo o curso do licenciado já atuar com estudantes com deficiências, sem conhecimentos teóricos prévios estabelecidos em qualquer uma das ementas apresentadas; e, por fim, Educação Física, com o aumento de componentes curriculares relacionados à Atividades Física Adaptada supera os demais no debate formativo acerca da formação docente para a Inclusão Escolar.

O conjunto dos PPC e componentes curriculares analisados revelou que a problemática, decorrentes da lacuna na formação inicial de professores da Educação Básica, em situação de Inclusão Escolar, está longe de ser superada. A não obrigatoriedade de estudos relacionados ao aprendizado e ensino de estudantes com deficiências, aliado ao conflito textual em não conseguir separar quando a Inclusão Escolar está relacionada ao estudante da graduação ou quando constitui em conhecimento necessário à formação do futuro professor da Educação Básica que atuará em salas de aulas inclusivas.

O paradoxo entre a exigência de professores com formação necessária descrita na Resolução CNE/CEB nº 2/200I (MEC, 200 I), prevista pela Resolução CNE/CP nº 2/20I 5 (MEC, 20I 5), e a forma como os PPC de licenciatura buscam atender a essa legislação aponta que, as mudanças nas políticas educacionais para construção de um sistema educacional inclusivo são insuficientes, porque esbarram na 
formação dos professores da graduação e pós-graduação, uma vez que a discussão do ensino, currículo e práticas pedagógicas para estudantes com deficiência é muito recente.

Ainda que a PNEE-EI/2008 (BRASIL, 2008) e o Decreto n 6.949/2009 (BRASIL, 2009) prevejam a importância dos cursos de licenciatura para a formação de professores na Educação Inclusiva, os dados analisados nos PPC de licenciatura da UFAL, Campus Maceió/AL, pouco impulsionam a melhoria da qualidade docente para assumir salas de aulas inclusivas. Apenas no caso da formação de professores com conhecimento da Libras foi possível percebermos avanços, a partir da obrigatoriedade instituída por Lei. Para a formação inicial do professor hoje é imprescindível que cada profissional em formação seja capaz de analisar o contexto em que desenvolve suas atividades e, planejá-las de forma coerente com as mudanças comumente efetivadas na sociedade inclusiva. Um ensino para todos deve atender as diferenças individuais, superando as desigualdades sociais e respeitando a diversidade dos sujeitos nos momentos de planejamento e prática educativa.

Este estudo demonstrou que é muito ingênuo, diante das análises realizadas nos PPC de licenciatura, atribuir o problema da inclusão escolar a uma resistência do licenciando por não se considerar apto ou preparado para ensinar ao estudante com deficiência, devido à pouca oferta do componente curricular Educação Espacial. O problema da defasagem curricular envolve a necessidade de que outros professores do curso, além do responsável pelo componente curricular Educação Especial ou equivalente, incluam em seus estudos teórico e práticos o ensino para a pessoa com deficiência.

No caso do PPC de Letras/Inglês, o ensino da Língua de Sinais deve ser o norte-americano ou britânico, mas não a interpretação da Libras, a não ser com relação ao componente curricular de ensino da Língua Portuguesa. Há muito para ser discutido, estudado e avançado em termos de currículo nos cursos de formação de professores, mas um novo cenário surge no realinhamento desta discussão, seja eliminando a necessidade de um componente curricular ou na orientação aos cursos de uma temática relacionada à educação da pessoa com deficiência nos vários componentes curriculares que compõem o PPC, sempre que for necessário.

Com isso, a proposta de analisar os PPC para compreender os desafios existentes na implementação da inclusão escolar, uma vez que para muitos autores o problema sempre recai na formação inicial dos professores da Educação Básica, foi desafiadora e significativa para estudos na área. As provocações e reflexões aqui postas apontam para um novo olhar dos estudos sobre a formação inicial de professores da Educação Básica. A implantação de componentes curriculares referentes à Educação Inclusiva na grade curricular dos cursos de licenciatura, assim como a reformulação dos currículos de acordo com a legislação vigente, é de extrema relevância.

Com essas medidas, o futuro profissional, além de conhecer o público-alvo atendido pelas políticas de inclusão, poderá desenvolver, em suas aulas, metodologias que possam atender às necessidades de 
cada estudante, com ou sem deficiência. O desafio de um currículo que atenda a Inclusão Escolar consiste na formação de professores que busca conhecer como estudante aprende e como torna-se capaz de auxiliá-los no percurso de aprendizagem e fortalecimento das potencialidades individuais.

\section{REFERÊNCIAS}

ALAGOAS. Matrículas e Infraestrutura: matrículas 2017.Disponível

em:https://www.qedu.org.br/estado/I02-alagoas/censo-

escolar?year $=2017 \&$ localization $=0 \&$ dependence $=0 \&$ education stage $=0 \&$ item $=$ matriculas. Acesso em: 31 jan. 2020

ALAGOAS. Matrículas e Infraestrutura: matrículas 20 I 8.Disponível em:https://www.qedu.org.br/estado/I02-alagoas/censo-

escolar? year $=2018 \&$ dependence $=0 \&$ localization $=0 \&$ education stage $=0 \&$ item $=$. Acesso em: 31 jan . 2020

ALVES, Maria Luiza T.; DUARTE, Edison. A percepção dos alunos com deficiência sobre a sua inclusão nas aulas de Educação Física escolar: um estudo de caso. Revista Brasileira de Educação Física e Esporte, São Paulo, v. 28, n. 2, p. 329-338, 2014.

BRASIL. Constituição da República Federativa do Brasil. Brasília, DF: Imprensa Oficial, 1988.

BRASIL. Política Nacional de Educação Especial. Brasília, DF. Ministério da Educação e do Desporto; SEESP, 1994.

BRASIL. Lei n 9.394, de 20 de dezembro de 1996. Lei de Diretrizes e Bases da Educação Nacional. Brasília, DF, 1996

BRASIL. Lei n 10. 436, de 24 de abril de 2002. Dispõe sobre a Língua Brasileira de Sinais - Libras e dá outras providências. Brasília, DF, 2002

BRASIL. Decreto $n^{\circ}$ 5.626, de 22 de dezembro de 2005. Regulamenta a Lei $n^{\circ} 10.436$, de 24 de abril de 2002, que dispõe sobre a Língua Brasileira de Sinais - Libras, e o art. 18 da Lei n 10.098, de 19 de dezembro de 2000. Brasília, DF, 2005

BRASIL. Política Nacional de Educação Especial na Perspectiva da Educação Inclusiva. Brasilia: MEC/Secadi, 2008

BRASIL. Decreto n 6.949, de 25 de agosto de 2009. Promulga a Convenção Internacional sobre os Direitos das Pessoas com Deficiência e seu Protocolo Facultativo, assinados em Nova York, em 30 de março de 2007. Brasília, DF. 2009

BRASIL. Lei n 13.005, de 25 de junho de 2014. Aprova o Plano Nacional de Educação - PNE e dá outras providências. Brasília, DF, 2015

BRASIL. Lei n 13.146, de 6 de julho de 2015. Institui a Lei Brasileira de Inclusão da Pessoa com

Deficiência (Estatuto da Pessoa com Deficiência). Brasília, DF, 2015 
BUENO, José Geraldo S. Crianças com Necessidades Educativas Especiais, Política Educacional e a Formação de Professores: generalistas ou especialistas? Revista Brasileira de Educação Especial. v. 3, n. 5, p. 7-25, 1999.

CHACON, Miguel C.M. Formação de Recursos Humanos em Educação Especial: respostas das Universidades à Recomendação da Portaria Ministerial n. 1793 de 27 dez. 1994. Tese (Doutorado em Educação). Faculdade de Filosofia e Ciências, Universidade Estadual Paulista, Marília, SP, 200 I.

LIBÂNEO, José Carlos. Pedagogia e pedagogos, para quê? São Paulo: Cortez, 1998.

LÜDKE, Menga; ANDRÉ, Marli E. Pesquisa em educação: abordagens qualitativas. São Paulo: EPU, 1986

MEC. Plano Decenal de Educação para Todos. Brasília: MEC, 1993

MEC. Portaria n 1,973, de 27 de dezembro de 1994. Brasília, DF. Ministério da Educação, 1994

MEC. Resolução CNE/CEB n² 2, de II de setembro de 200 I Institui as Diretrizes Nacionais para a Educação Especial na Educação Básica. Brasília, DF: Ministério da Educação. Conselho Nacional de Educação, 200।.

MEC. Resolução CNE/CP n I, de 18 de fevereiro de 2002. Institui as Diretrizes Curriculares Nacionais para a formação de professores da educação básica, em nível superior, curso de licenciatura, de graduação plena. Brasília, DF: Ministério da Educação. Conselho Nacional de Educação, 2002

MEC. Resolução CNE/CES n 3, de 08 de março de 2004. Aprova as Diretrizes Curriculares Nacionais do Curso de Graduação em Dança e dá outras providências. Brasília, DF: Ministério da Educação.

Conselho Nacional de Educação, 200 I.

MEC. Resolução CNE/CEB n 4, de 02 de outubro de 2009. Institui Diretrizes Operacionais para o Atendimento Educacional Especializado na Educação Básica, modalidade Educação Especial. Brasília, DF. Ministério da Educação, Conselho Nacional de Educação, 2009

MEC. Resolução CNE/CEB n², de 01 de julho de 20I5. Define as Diretrizes Curriculares Nacionais para a formação inicial em nível superior (cursos de licenciatura, cursos de formação pedagógica para graduados e cursos de segunda licenciatura) e para a formação continuada. Brasília, DF. Ministério da Educação, Conselho Nacional de Educação, 2015

MENDES, Enicéia G. Caminhos da Pesquisa sobre Formação de Professores para a Inclusão Escolar. In: ALMEIDA, Maria Amélia; MENDES Enicéia G.; HAYASHI, Maria Cristina P. I. Temas em Educação Especial: múltiplos olhares. Araraquara, SP: Junqueira \& Marin; Brasília, DF: Capes/Proesp, 2008, p. 7582

ONU. Resolução ONU n² 217-A de 10 de dezembro de 1948. Assembleia Geral das Nações Unidas em Genebra.

ONU. Declaração Universal dos Direitos Humanos. Assembleia Geral das Nações Unidas em Paris. 10 dez. 1948.

PEDROSO, Cristina C. A.; CAMPOS, Juliane. A. P. P.; DUARTE, Marcia. Formação de professores e educação inclusiva: análise das matrizes curriculares dos cursos de licenciatura. Educação Unisinos. v. 17 , n. I, p.40-47, 2013.

PIMENTA, Selma G.; LIMA, Maria Socorro L. Estágio e docência. São Paulo, SP: Cortez, 2012 
RODRIGUES, David. et al. (Orgs.). Educação inclusiva e necessidades educacionais especiais. Santa Maria, RS: EdUFSM, 2005.

UFAL. Projeto Político Pedagógico do Curso de Pedagogia. Maceió, AL: Universidade Federal de Alagoas. Centro de Educação, 2006a.

UFAL. Projeto Pedagógico do Curso de Graduação em Educação Física Licenciatura. Maceió, AL: Universidade Federal de Alagoas. Centro de Educação, 2006b.

UFAL. Projeto Pedagógico do Curso de Matemática Licenciatura. Maceió, AL: Universidade Federal de Alagoas. Instituto de Matemática, 2006c.

UFAL. Projeto Pedagógico do Curso de Música Licenciatura. Maceió, AL: Universidade Federal de Alagoas. Instituto de Ciências Humanas, Comunicação e Artes, 2006d.

UFAL. Projeto Pedagógico do Curso de Licenciatura em Química. Maceió, AL: Universidade Federal de Alagoas. Instituto de Química e Biotecnologia, 2007.

UFAL. Projeto Pedagógico do Curso de História Licenciatura. Maceió, AL: Universidade Federal de Alagoas. Instituto de Ciências Humanas, Comunicação e Artes, 2015.

UFAL. Projeto Pedagógico do Curso de Licenciatura em Dança. Maceió, AL: Universidade Federal de Alagoas. Instituto de Ciências Humanas, Comunicação e Artes, 2016 a.

UFAL. Projeto Pedagógico do Curso de Licenciatura em Letras Francês. Maceió, AL: Universidade Federal de Alagoas. Faculdade de Letras, 2016b.

UFAL. Resolução Consuni/UFAL n 6, de 19 de fevereiro de 2018. Define os Componentes Curriculares Comuns aos Cursos de Graduação de Formação de Professores para a Educação Básica, no Âmbito da UFAL. Maceió, AL. Universidade Federal da Alagoas, Conselho Universitário, 20। 8a.

UFAL. Projeto Pedagógico do Curso de Ciências Sociais Licenciatura. Maceió, AL: Universidade Federal de Alagoas. Instituto de Ciências Sociais, 20 I8b.

UFAL. Projeto Pedagógico do Curso de Letras Inglês Licenciatura Presencial. Maceió, AL: Universidade Federal de Alagoas. Faculdade de Letras, 2018c.

UFAL. Projeto Pedagógico do Curso de Licenciatura em Letras Português. Maceió, AL: Universidade Federal de Alagoas. Faculdade de Letras, 2019a.

UFAL. Projeto Pedagógico do Curso de Letras Espanhol Licenciatura. Maceió, AL: Universidade Federal de Alagoas. Faculdade de Letras, 2019b.

UFAL. Projeto Pedagógico do Curso de Física Licenciatura. Maceió, AL: Universidade Federal de Alagoas. Instituto de Física, 2019c.

UFAL. Projeto Pedagógico do Curso de Teatro Licenciatura. Maceió, AL: Universidade Federal de Alagoas. Instituto de Ciências Humanas, Comunicação e Artes, 2019d.

UFAL. Projeto Pedagógico do Curso de Geografia Licenciatura. Maceió, AL: Universidade Federal de Alagoas. Instituto de Geografia, Desenvolvimento e Meio Ambiente, $2019 \mathrm{e}$.

UFAL. Projeto Pedagógico do Curso de Licenciatura em Ciência Biológicas. Maceió, AL: Universidade Federal de Alagoas. Instituto de Ciências Biológicas e Saúde, $2019 f$. 
UNESCO. Declaração Mundial de Educação para Todos e Plano de Ação para Satisfazer as Necessidades Básicas de Aprendizagem. Conferência Mundial sobre Educação para Necessidades Especiais, 1994, Salamanca (Espanha). Genebra: Unesco, 1994.

UNICEF. Declaração Mundial de Educação para Todos. Conferência de Jomtien, Tailândia. UNICEF, 1990.

VITALIANO, Célia R; DALL'ACQUA, Maria Julia. Análise das Diretrizes Curriculares dos Cursos de Licenciatura em Relação à Formação de Professores para Inclusão de Alunos com Necessidades Especiais. Revista Teias. v. 13, n. 27, p. 103-121, jan./abr. 2012.

VITALIANO, Célia R. Diagnóstico das necessidades de preparação dos professores de cursos de licenciatura para incluir estudantes com necessidades especiais e formar professores aptos a promover a inclusão. In: ALMEIDA, Maria Amélia; MENDES Enicéia G.; HAYASHI, Maria Cristina P. I. Temas em Educação Especial: múltiplos olhares. Araraquara, SP: Junqueira \& Marin; Brasília, DF: Capes/Proesp, 2008, p. 246-255.

\section{COMO CITAR ESSE ARTIGO}

\section{Associação Brasileira de Normas Técnicas (ABNT)}

MERCADO, Elisangela Leal de Oliveira; PEREIRA, Karla Maria Martins Santos; DIVINO, Liziane Medeiros Nascimento do Amor. Análise dos Projetos Pedagógicos dos Cursos Licenciatura: estamos preparando professores para lecionar estudantes com deficiência?. Debates em Educação, Maceió, v. I2, p. 292-3 |4, dez. 2020. ISSN 2175-6600. Disponível em:

https://www.seer.ufal.br/index.php/debateseducacao/article/view/l044l. Acesso em: dd mmm. aaaa.

\section{American Psychological Association (APA)}

Mercado, E., Pereira, K., \& Divino, L. (2020). Análise dos Projetos Pedagógicos dos Cursos Licenciatura: estamos preparando professores para lecionar estudantes com deficiência?. Debates em Educação, I 2(Esp2), 292-3 |4. doi: https://doi.org/10.28998/2 I75-6600.2020vI2nEsp2p292-3|4 